5. On some new and insufficiently known Species of Marmoset Monkeys from the Amazonian Region. By Prof. Dr. Emil A. Goeldi, C.M.Z.S., Director of the Pará Museum.

[Received November 23, 1906.

\title{
(Text-figures 20-23.)
}

On the occasion of the Sixth International Zoological Congress, held at Berne (Switzerland) in August 1904, I presented a paper, "Nova zoologica from the Amazonian Region, dealing especially with new 'Vertebrates," in which I discussed at some length new and little-known representatives of the family of Callitrichidæ (Hapalidæ, auctorum*) from the Upper Amazon, especially from the Rio Purús, as follows:-(1) A species of Midas whose close relationship with Midas rufiventer Gray I recognised at first sight, and to which later on, after comparing it with the type-specimen of this latter in the British Museum in London (at the time of my visit to the International Ornithological Congress in July 1905), I decided to give the name of Midas griseovertex. (2) A second species of Midas, evidently related to M. labiatus Geoffr. (1812), M. illigeri (id. 1845), and $M$. weddellii (id. 1849), and having as its most characteristic distinguishing feature an enormously long white moustache, which afterwards, on the same occasion, I decided to name Midas imperator. (3) Midas pileatus, described by Geoffroy in 1848 from the original specimen from the Rio Javary, kept in the Paris Museum, and until recently not represented in any other Museum, so far as could be judged from current zoological literature. I was then able to show a splendid pair of this very rare species. (4) Midas fuscicollis, described so long ago as 1823 by Spix, but only from immature specimens, the habitat of the adult animal of both sexes having escaped notice, as it appears, in a surprising manner until 1904. (5) Midas mystax Spix, originally described from the Rio Solimoẽs, represented in my exhibited collection by a very dark specimen from the Rio Juruá.

One of the essential conditions for arriving at certainty in my conclusions, as above suggested, was the careful examination of certain individuals kept as type-specimens in the British Museum. The purpose of the present article is principally to record the result of my investigation in this respect, which proves to be most interesting and instructive. To say it at once: the most remarkable and unexpected discovery was the fact, that of the two specimens of Midas rufiventer, type and quasi co-type, on the shelves in the British Museum, the latter does not coincide with the former, but, on the contrary, should constitute the typespecimen of a new, overlooked, and undescribed species of the genus Midas.

* See Thomas, Ann. Mag. N. H. (7) vol. xii. (1903). 
Midas thomasi, sp. n. (1905).

[Labelled in the British Museum: "Midas rufiventer, o", 'The red-bellied Tamarin,' Upper Amazonia. W. Bates. Exp. 1857 a. Tunantins, north side of Amazons."]

Dorsal ASPECT. - Anterior half of a dark, deep blackish-brown colour (somewhat like the half-grown $M$. fuscicollis), extending from behind the ears as far as the middle of the back. Hinder half of the same brown, the tips of the hairs being however mottled with a lighter greyish-brown, but in a much less pronounced degree than in the typical $M$. rufiventer.

Head (text-fig. 20) black, with an insignificant median small light spot beginning just between the ears, behind the vertex; a still less noticeable lightish dash, consisting only of a few greyish hairs, almost forming an anterior continuation, is perceptible in the same median line just in front of the former. Details of the region of mouth and nose as in the type of M. rufiventer.

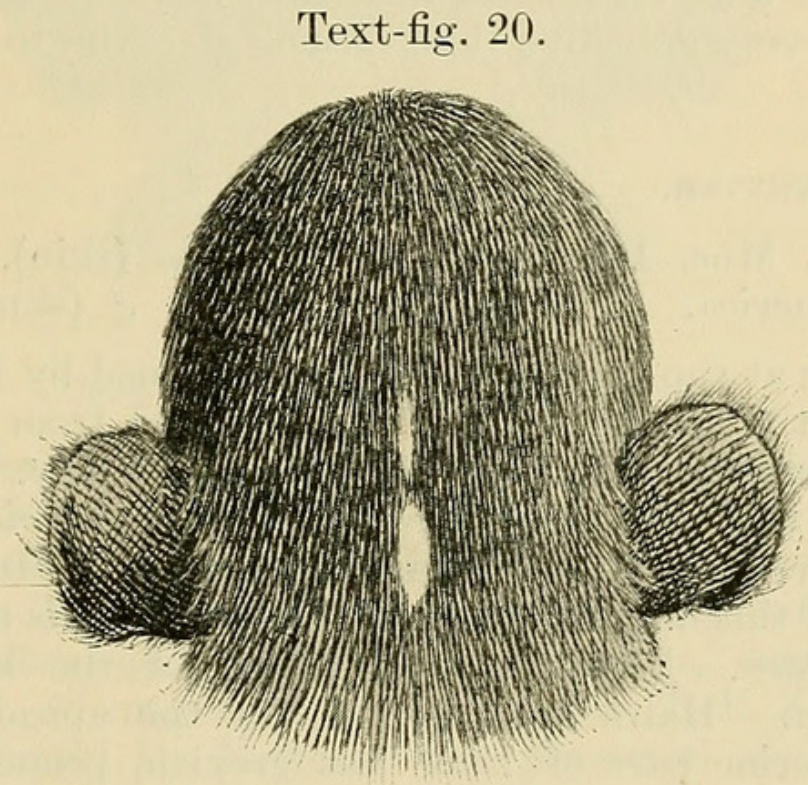

Back view of head of Midas thomasi.

Arms dark blackish-brown, passing into a true black towards the hands, not being, however, a brilliant black as in the M. rufiventer type.

Legs. Exterior side of thighs of the same colour as the posterior half of the back, turning to black toward the feet.

Tail black.

Ventral ASPECT. - Anteriorly a cross-zone of light reddishyellow (viz., inside of arms and a band across the breast as wide as the insertions of the arms). Rest from there backwards reddish rust-yellow (lighter than in the new species $M$. griseovertex G., and much lighter than in $M$. rufiventer type).

The light under side is abruptly separated in the region of the neck and breast from the black of the neck and head. (This light abdominal colour cannot be attributed to fading of an old 
Museum specimen, perhaps unduly exposed to light on the shelves, because in that case such change would certainly be even more noticeable in the colouring of the back, which, although more exposed, still holds however its colour fast; consequently the impression is produced of a decidedly distinguishing character of specific rank.) The light abdominal colour extends to the under side of the insertion of the tail, as in $M$. rufiventer type and in the other new species, $M$. griseovertex.

On separating the fur the deeper portion is of the dark colouring, which is lighter in the anterior than in the posterior half of the body, and thus corresponding perfectly with the scale of colouring of the external aspect of the fur.

The only existing specimen (stuffed) dates, as noted above in the copy of the label, from Tunantins, Upper Amazon, where it had been collected in 1857 by Henry W. Bates.

Let us now proceed to the description of the type-specimen of the true Midas rufiventer Gray, in the British Museum, in order to relieve once for all the deplorably embarrassing situation caused by the very defective descriptions given up to the present time.

\section{Midas Rufiventer.}

["Brit. Mus. Reg. 43.10.12.6. Type (skin). Locality: South America. Purchased of Argent. ơ (skull)."]

I must state at the outset, that I was informed by Mr. Oldfield Thomas that the specimen had been obtained from a dealer, a fact which accounts for the vagueness of the locality.

In general the results of my examination coincide with the description given by Gray in his 'Catalogue of Monkeys, etc.' 1870, p. 66 , of this original specimen, only that it is too brief.

DoRsal ASPECr.-Predominating colour of the back a dark blackish-brown. Hairs light greyish for the apical $\frac{1}{6}$ of their length. Anterior part of back less greyish, posterior part of back more so. The fur down to the roots dark brown (not light greyish-brown).

Head (text-fig. 21). General colouring of the head a deep black, not blackish-brown. Mouth bordered with sparse whitish hairs. Central zone between and beneath the nostrils sparsely covered with lightish grey hairs (not brilliantly white).

A spear-shaped dark rust-red median stripe extending from the vertex between the ears downward to the insertion of the nose, the rust-red being of the same intensity as the colour of the whole abdominal side. From the vertex backward, in form of a double ploughshare, over the occiput down to the neck spreads out a patch of a greyish-brown colour, which combined with the lanceshaped frontal marking forms a comparatively broad triangle with a tendency to lateral posterior development.

Arms. Outer side deep dark brown (like the head), slightly lighter on the upper arm. 
Legs. Outer side of the same colour as the posterior part of the back.

Ventral ASPECT.-General colour a deep dark chestnut reddishbrown, considerably darker than in the Purús species, $M$. griseovertex.

Tail very long, dark blackish-brown, turning blacker toward the end.

Text-fig. 21 .

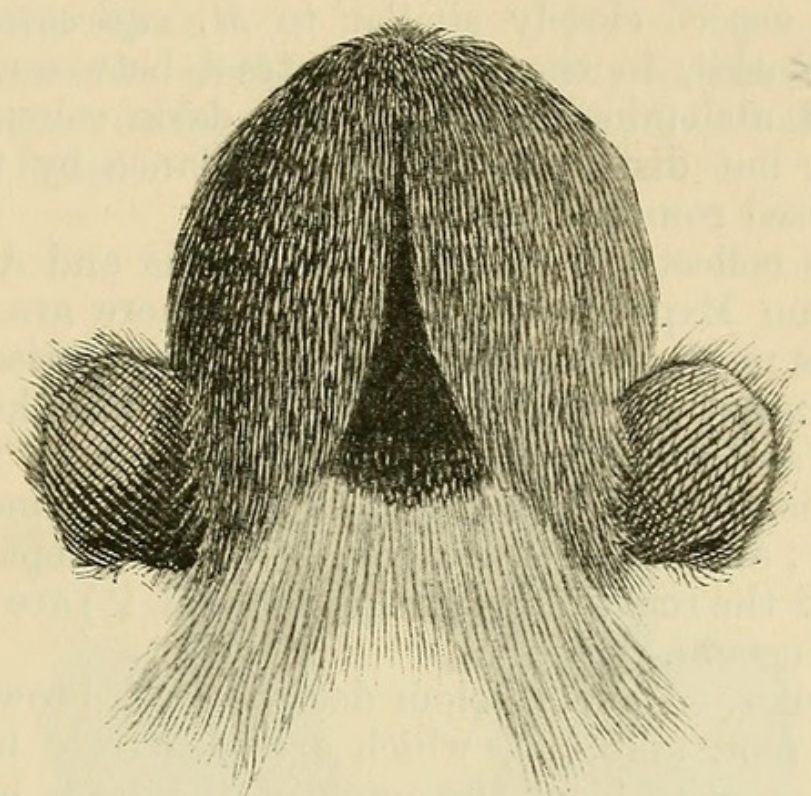

Back view of head of Midas rufiventer.

So far as I know the only figure as yet published of a specimen of Marmoset Monkey, closely resembling this type-specimen of Midas rufiventer in the British Museum, is that in the supplementary plate 36 of the work of Reichenbach, under the name of "Midas erythrogaster Natterer, Mus. Vindob.," made, as stated on p. 14, from an original sketch by a Mr. T. E. Zimmermann of a skin collected by Natterer and preserved in the Vienna Museum. With no little surprise I discover, however, that Pelzeln, the excellent monographer of the Brazilian mammals collected by Natterer, enumerates this very specimen, and also the figure in Reichenbach, as synonyms under the head of Midas labiatus Geoffroy, a procedure which seems to me more than doubtful, not to say flatly erroneous. In this figure, though worthy of criticism in some respects (the most salient defect being the substitution of the delicate mottling by rough daubs of black on a greyish ground), one essential feature nevertheless stands out clearly, namely the rust-coloured frontal spot, coinciding perfectly with the abdominal colour.

I have never been able to consult either the full description, or any figure, or any other useful information concerning the M. elegantulus Slack, Proc. Academy of Natural Sciences of Philadelphia, 1861 , p. 463 , always quoted as a synonym of M. rufiventer Gray. 
Having now finished these explorations of the treasures stored up in the British Museum as an essential preliminary and solid basis for the discussion of the respective questions that arise, I will proceed to the detailed description of the two new species of Marmoset Monkeys of the Purús Region, mentioned at the beginning of the present article.

\section{Midas gRiseovertex, sp. n.}

In general aspect closely similar to $M$. rufiventer Gray and $M$. thomasi Goeldi, in the sharp contrast between the bright rusty-coloured abdominal side and the dark colouring of the dorsal aspect, but distinguishable at a glance by the greyishwhite, good-sized rounded frontal patch.

Among the collections made in the Purús and Acre Regions by our Museum Expeditions (1903-1904) there are seven individuals of this most interesting and well characterised species of Marmoset Monkey (skins, skulls of all and trunks of some), 4 being males and 3 females. One mounted pair ( 0 q $q$ ) remained in the Museum at Berne, labelled as above ; three mounted individuals $(\delta, q$, and a half-grown young one) are kept in the Pará Museum ; and the remaining pair of skins ( $\left.\sigma^{*}+q\right)$ are intended for the British Museum.

DORSAL ASPECT.-General colour deep blackish-brown, excepting head, hands, feet, and tail, which are positively black. This colour remains pure from the nape of the neck backward for one-third of the length of the back. The hinder two-thirds of the back shows a mottling due to the light greyish tips of the hairs, which terminal points measure about $\frac{1}{6}$ of the entire length of the hair and are slightly longer toward the hips; the intensity of the mottling increasing gradually backwards, being most pronounced in the sacral region, presenting even a whitish appearance, when seen from certain oblique directions.

On separating the fur in the region of the shoulders, the impression of colour is in general the same as the exterior, that is deep blackish-brown, excepting that the lower third of the hairs towards the roots forms a slightly lighter zone, especially laterally to the median line. Making the same examination in the region of the hips, the light zone is scarcely apparent, the fur being of the general colour almost down to the roots.

Head. General colour sooty-black. A narrow zone of whitish hairs bordering the whole extent of the mouth. In the region of the upper lip the white zone rises in a very conspicuous triangular zone, with its broad base resting on the circular white band of the mouth. One very noteworthy feature of this triangular zone is that the lateral oblique lines cross exactly the middle of the nostrils, so that the exterior half of each falls in the blackish region, the interior half in the whitish triangle.

At the vertex, from a line connecting the anterior borders of the ears, commences a whitish patch (text-fig. 22), occupying 
about $\frac{1}{3}$ to $\frac{2}{5}$ of the width between the ears and widening slightly backwards, but in no specimen acquiring the double ploughshareshape of the rust-coloured patch of the Midas rufiventer type. In young individuals this patch is rather more greyish, while in more aged specimens it becomes nearly white. In length it extends as far as the posterior border of the occipital region.

Arms. Outer side from shoulder to elbow of the same sooty blackish-brown as the whole shoulder region; fore-arms and hands decidedly black.

Legs. Outer side of the same intensely mottled colour as the entire hip-region as far as to the foot; the foot itself of the same black as the hand.

\section{Text-fig. 22 .}

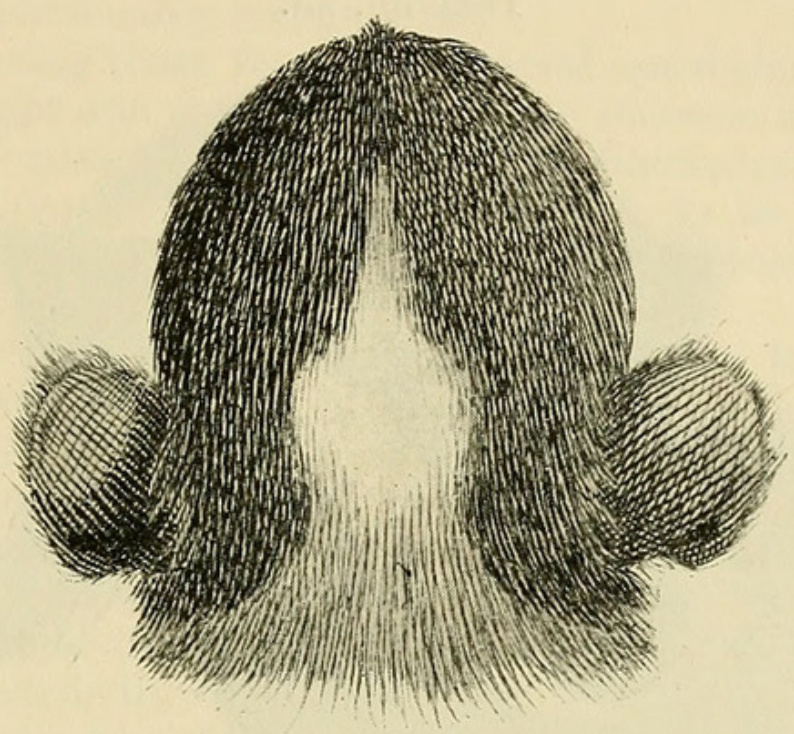

Back view of head of Midas griseovertex.

Ventral ASPECT.-General colour light reddish rusty, decidedly lighter than in Midas rufiventer. It embraces the whole area from the middle of the throat, breast, and belly, inner side of arms and legs, and a short distance beyond the insertion of the tail on its under side (some $5 \mathrm{~cm}$.). On the flanks the dorsal and ventral colours are very abruptly separated, it being noteworthy that the rusty-coloured hairs of the abdominal side are only about half as long as the adjacent dark-coloured hairs of the dorsal part.

Tail long, exceeding the length of the body by that of the head. Colour the same black as of the fore-arms and hands, but here and there with rows of hairs with light brownish tips, which may be interpreted probably as the vestiges of an annular arrangement.

MidAs IMPERATOR, sp. n.

In general aspect, especially in colour, somewhat similar to M. labiatus Geoffr., M. illigeri, and $M$. weddellii, but easily distinguished by the immense white moustache, which becomes 
phenomenal especially in the adult male. (Text-fig. 23 represents the head of an old male individual.)

Ouj Purús collections embrace five skins (and skulls) (3ठ 0 , 2 오 오), two from the Rio Acre and three from the upper Rio Purús. A family of three individuals ( 0 o adults, and a young one) are already mounted in the Pará Museum; the two remaining $(\sigma, q)$ skins, of half-grown specimens, are destined to be sent to the Museums of Berne and London respectively.

This species is distinguished by a more or less pronounced reddish greyish-brown general colour of the dorsal side, light rustcoloured abdominal side, dark feet, hands, and head, excepting the white circumbuccal zone and the skull-cap, which tend to become grey with age.

\section{Text-fig. 23.}

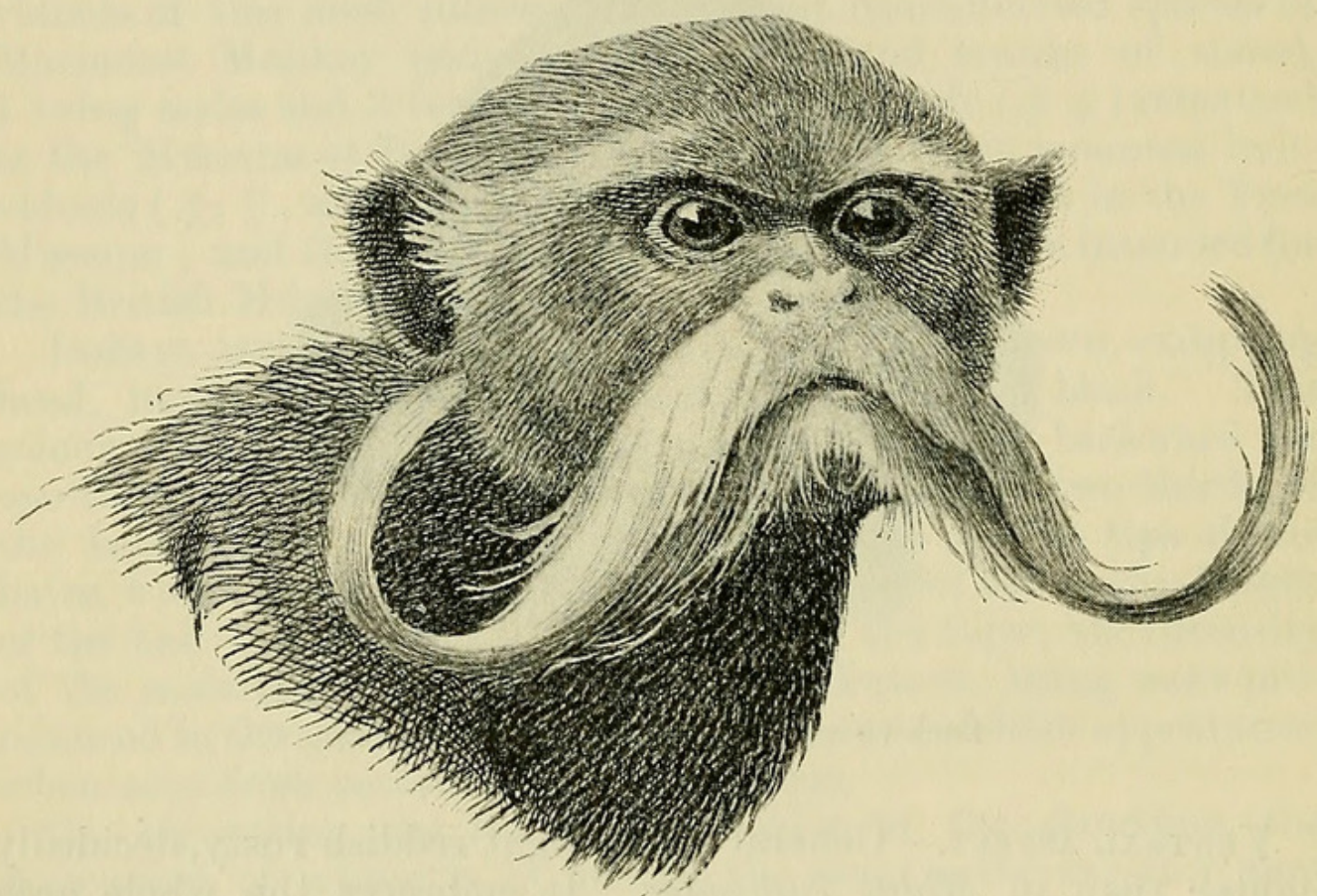

Head of Midas imperator.

DORSAL ASPECT. - The reddish-rust colour is more conspicuous in the above mentioned old male, and is already noticeable in the two young males (one stuffed in the Pará Museum and one skin). General colour as above stated; it may be noted, however, that the greyish tinge, in the same way, is more pronounced in the female.

On separating the fur nearly every one of the five specimens presents a slightly different appearance. In the two adult stuffed specimens in the Pará Museum the lower half is uniformly dark; the outer half shows alternately a light zone, then a dark one, followed by a light one and a dark one, the terminal zone being: again lighter, making five zones of equal breadth in the outer half and giving the general impression of two equal pairs of light and dark zones. 
Examining in the same manner the two skins of half-grown individuals $\left(q, \sigma^{*}\right)$, we see immediately, that while the lower half is dark as above, the outer half shows alternately a light zone, then a dark one, and finally the terminal lighter one, giving: as a total result the impression of only one complete pair of light and dark zones. The female skin presents nevertheless a peculiarity in the circumstance that near the roots of the hairs there is an unmistakable trace of a basal light zone-a peculiarity of this one individual among all the five known.

Proceeding now to the examination of the same details in the quite young stuffed specimen of the mounted family in the Pará Museum, the general impression is of only one well-marked pair of dark and light zones, from within outwards, while on closer inspection the second outer pair noticed in the half-grown specimens is unquestionably recognisable.

Recapitulating these facts, the general conclusion is that the number of light and dark zones tends to increase with age. We have here one more useful hint, that in the discrimination of species prudence is required in judging the value to be attributed to such variations in colour, which in the present case can be fairly proved to be due to differences of age and sex.

Head. All parts of the full front view of the face and direct lateral view are sooty-black in the adult female, the quite young individual $(\delta)$ and the two skins ( $\sigma q$ ), while the old male shows the face somewhat mixed up with greyish-brown hairs. The circumbuccal zone, however, is again an exception from this general colour, being saliently pure white. This zone is relatively broader than in any of the preceding species, including the entire nostrils in the old male, while in the other four specimens the border-line of the white colour curves below the nostrils, arising again on the ridge of the nose at about one-third of its length. The same white colour characterises the phenomenal moustache, which already in infant specimens is of a greater length than in any other of the moustached species known to me. The old male (text-fig. 23), however, beats the world's record, the longest hairs attaining a length of no less than 57 to $60 \mathrm{~mm}$. !

My collectors inform me that the moustache is worn in life not straight, but with the modern upward twist. The two oldest specimens show the strange strong development of the white hairs of the circumbuccal zone extending even over the whole area of the lower jaw, not including the chin and inferior side of the jaw. As a result, the old males appear bearded as well as moustached.

In the three younger individuals the crown of the head is brownish-black, with a tendency towards forming the already familiar favourite lighter-coloured patch of a pale brownish shade. In the adult female the patch is diamond-shaped, almost dirty greyish-white, and therefore very conspicuous. In the old male a pronounced greyish cast spreads all over the top of the head, without forming any distinct patch.

Arms. Outer side of upper arm the same colour as the back, 
but a little lighter in all specimens. Fore-arms and hands gradually darker towards the extremity. This is especially the case in the three young specimens and the old female, while the male shows on the outer side of the fore-arm and hands the same dark greyish cast as noted above in the description of his face.

Legs. Outer side of thigh the same colour as the back, but as a rule a little lighter, especially in the old female. The outer side of the foot is of the same dark colour as the hand.

VENTRAL ASPECT.-The colour forms a marked contrast with that of the dorsal aspect, by having a pronounced tendency towards a rusty red, especially in the younger specimens. This rusty-red shade covers the whole under side, from the throat backward including the inner side of the arms and legs and no small extent of under side of tail. The same colour tends to form regions or patches of a deeper shade, one between the arms, covering the chest, and another between the legs, covering the abdomen and surrounding the anus. The chest-patch, especially in the old female, looks as if soiled by dried blood.

Tail. The tail is long, nearly half as long again as the body (the average length of four specimens measured being as $11: 8$ ). In the younger specimens the dorsal side nearly from the insertion to the end is of the same dark colour as the feet, while the lower side shows a gradually narrowing line of the above mentioned deep rusty red fading toward the extremity. In the adult specimens the colour of the tail tends to become uniform in its whole circumference. In the old female the upper side is darker than the lower at least for two-thirds of its length, the terminal third being of a dark grey, due to the black roots and the light tips of the hairs. The under side for about half its length has the general light rusty-red colour of the ventral aspect, the terminal half being alike on the dorsal and ventral side, a dark grey.

Most aberrant is the colouring of the tail in the old male. From the very insertion the bright rusty-red colour predominates in its whole circumference throughout its entire length with the exception of a dark terminal tuft. The rusty red is most noticeable to a certain extent (one-eighth) from the insertion backward. Approaching the end the colour is more mixed with dark, owing to the greater extent of black at the roots of the individual hairs. A darker isolated patch exists also on the second eighth.

\section{Midas fuscicollis Spix.}

This species, it is true, was long ago described, having been introduced into science in 1823 by the Bavarian explorer J. von Spix from individuals obtained on the Rio Javary, but it is evident from our much richer material (eight specimens, $6 \sigma^{\star} \sigma^{\star}$ and 2 욱), collected on the Rio Purús, that the pelage of the full-grown animal has never been properly described and figured. Referring to a comparison of the two figures 3 (adult coat) and $3 a$ (juvenile coat) of my original coloured Marmoset- 
Monkey plate, presented to the Zoological Congress at Berne and now being reproduced for a separate publication, it is especially noticeable that the adult coat is distinguished by the deep blackishbrown colour of the anterior part of the body.

Briefly described, the colour of a typical adult male is as follows :-

Dorsal aspect of anterior part of body, as far back as behind the shoulders, of a uniform sooty brownish-black. On separating the fur, two-thirds of the length of the hairs is lighter, greyish or dirty white near the roots, pale greyish-brown outwards, the outer third shading into the above-mentioned brownish-black, without presenting any tendency to zonal arrangement. The posterior part of the body presents a mottled appearance, due to the intervention of yellowish-reddish zones. On separating the fur in this region, two-thirds of the length of the hair is quite uniform dark; the last third is about equally divided between the light zone and a black terminal one.

Singularly deep rusty-red are the rump and thighs. This is due to the absence of the dark terminal zone of the hairs in this region, each hair being black at its base, and the terminal third entirely rusty. Tail, arms, and feet black.

Dorsal and ventral aspects are noticeably divided by a lateral rusty-red stripe of shorter hairs on each side, running from the arm-pit to the flank. The real median ventral stripe, wider than the just-mentioned lateral one, again assumes the dark brown colouring of the anterior part of the body.

In the face the most salient features are the white eyebrows, meeting in the median line at the base of the nose, forming a very striking double crescent. Circumbuccal zone whitish, more extensive than in all the preceding species, but not so sharply outlined.

Midas pileatus Is. Geoffroy et Deville.

This species was figured in 1848 by Geoffroy in the 'Archives du Muséum,' vol.v. pl. 31, and described under the name of " Tamarin à calotte rousse," p. 569. Up to the time of my paper read at Berne, at the International Zoological Congress, it seemed to me, judging from the literature within my reach, that it was represented only by the single original specimen, coming from the Rio Javary, and preserved in the Paris Museum. (I saw it there some days before, without a label, stowed away on a side-shelf.)

At that time we had obtained from the upper River Purús two other specimens, a pair. This splendid species has its chief distinguishing marks in the cinnamon-coloured sealp-patch, the brownish-black general colour, and the sharply outlined white circumbuccal zone, including the nostrils, which are completely surrounded by a narrow white band.

Being in London for the Meeting of the Fifth International Ornithological Congress in July 1905, Mr. Oldfield Thomas, of the

Proc. Zool. Soc.-1907, No. VII. 
department of mammals at the British Museum, to my no small surprise showed me a small series of skins from different points in the Upper Amazon region, one having been furnished by Dr. von Thering, from the River Juruá expedition.

After my return to Pará I saw by the 'Revista do Museu Paulista,' vol. vi. (1904), p. 416, which had been sent in my absence, that Dr. von Thering refers to three individuals in the collections made by Mr. Garbe at the time of the above mentioned Juruá trip. He, however, classifies it as a new subspecies $-M$. pileatus juruamus - which according to his statement is distinguished by the dark colour of the hair of the back, which in the description of the original type-specimen, made by Geoffroy, is stated to be reddish at its base. It is true, that Geoffroy expresses himself in the following terms :- " Le corps est supérieurement recouvert, ainsi qu'on l'observe si souvent chez les Hapaliens, de poils roux dans la plus grande partie de leur étendue, annelés de blanchâtre et de noire vers la pointe. Il resulte de cette disposition, chez $M$. pileatus, un mélange de gris et de noir, mais non des bandes alternatives de l'une et de l'autre couleur." Although the adjective "roux" may not be perhaps a happy term, the rest of the description and the figure itself indicate an animal which does not differ essentially from the specimens examined by me in London, nor from my two mounted specimens here at Pará. Geoffroy evidently wrote with the desire to differentiate the uniform general colouring of this species (which, as already seen, is usually a common feature of most Amazonian Callitrichidæ) from the distinctly striped colouring of certain southern Marmoset Monkeys (Hapale jacchus, \&c.).

On separating the fur of the back of my two individuals in the Pará Museum, the hair appears to be of the same deep blackishbrown as in the case of $M$. griseovertex. The terminal fourth then shows a light greyish-white zone, followed by a terminal nearly black one. It follows therefore that in this detail my Purús specimens accord with the Juruá specimens of Ihering. However, this detail does not seem to me of sufficient weight to justify the establishing of a separate subspecies.

\section{Midas mystax Spix.}

Acquaintance and description of this species date from the same period and come from the same source. Spix brought his specimens from the River Solimoẽs ; a female is figured on plate 22 of his work. Our Museum possesses a considerably darker male specimen from the River Juruá.

Instead of entering into a detailed description, I would simply call attention to the characteristic fact, that the white circumbuccal zone is nearly identical in extent and form with that of the preceding Midas pileatus, but with a stronger tendency to form a moustache. 
Midas illigeri Pucheran.

I have recently received, through the kindness of the wife of the German Consul at Pará, Dr. Olshausen, an example of another species of Amazonian Marmoset Monkey hitherto unrepresented in our collections. It had been obtained at a very early age from an Indian woman at Iquitos, and kept as a pet until its mistress was about to sail for Europe. It lived several months at the Museum until about half-grown, and is now mounted.

DoRSAL ASPECT.-Principal colour a lovely dark brown-red covering the nape of neck, shoulders, and outer side of arms and legs. embracing with a small band the rump and base of the tail. The back, however, properly speaking, forms an exception to this colour, bearing a very long oval patch, distinctly outlined, of dirty black in the centre and greyish borders, with the tendency to form posteriorly dimly apparent light and dark transverse bands. Head, hands, feet, and tail black.

VENTRAL ASPECT.-Uniformly brownish-black from the throat as far as the anus, embracing the inner side of arms and legs, separated from the dorsal patch by a brownish-red margin.

In the black face we again find the white circumbuccal zone. But in this case it leaves the nostrils free and the white runs up to the cheeks in a triangular form nearly as far as the outer corner of the eye.

By this feature the animal immediately proves to belong to the group $b$, subdivision $a$ of the classification of Schlegel ('Singes,' p. 262), that is to say to the Hapale devillei group. Among all the figures I have at my disposal, my specimen corresponds best with the animal represented in plate 13 of the 'Proceedings of the Zoological Society,' 1871, by Bartlett, with the designation of Midas devillei of (considerably better than with the figure of $M$. devillei, fig. 3, plate 6, in the 'Atlas' of Castelnau, which lacks any trace of a distinctly coloured dorsal patch). As the animal there represented is attributed by Schlegel ('Singes,' p. 263) and by Forbes ('Handbook of Primates,' p. 145 seq.) to Hapale illigeri Pucheran (' Revue de Zoologie,' 1845, p. 336), and as the description of this species given by these two authors coincides satisfactorily with my Iquitos individual, I think I have to do with a half-grown specimen of Midas illigeri Puch., a Marmoset Monkey stated to be fairly abundant in the Peruvian Amazons. 
February 5, 1907.

His Grace The Duke of Bedford, K.G., President, in the Chair.

Mr. F. Martin Duncan, by permission of the Charles Urban Trading Co., Ltd., gave a cinematograph exhibition of animals in the Society's Gardens and other zoological subjects, chiefly the life-history of Insects.

Mr. Oldfield Thomas, F.R.S., F.Z.S., exhibited a collection of Mammals and Birds from the Islands of Saghalien and Hokkaido, N. Japan, made by Mr. Malcolm P. Anderson in carrying out the Duke of Bedford's Exploration of Eastern Asia. Mr. Thomas proposed to give a full account of the Mammals on a later occasion.

Dr. W. T. Calman, F.Z.S., read a paper entitled "On new or Rare Crustacea of the Order Cumacea from the Collection of the Copenhagen Museum. Part I. The families Bodotriida, Vauntompsoniidce, and Leuconidce."

This paper will be published entire in the 'Transactions.'

The following papers were read :-

1. The Origin of the Lateral Horns of the Giraffe in Fœtal Life on the Area of the Parietal Bones. By E. RAy LANkester, M.A., D.Sc., LL.D., F.R.S., F.Z.S., Director of the Natural History Departments of the British Museum.

[Received February 5, 1907.]

(Text-figures 24-36.)

A remarkable and wide difference between the Giraffe and the Okrpi is constituted by the position and relation of the lateral horns in these two animals in regard to the bones of the skull. As I pointed out in my memoir on the Okapi read in 1901 (Trans. Zool. Soc. vol. xvi. p. 279), the bony horn-cone of that animal is attached to the frontal bone, and it is the frontal bone which is raised into a boss for its support, whilst even in the hornless skulls supposed to be those of the female these frontal bosses are present. On the other hand, in the young Giraffe the main axis of the lateral "ossicone"* falls within the area of the parietal bone

* I use the term "ossicone" in the present paper for the independently ossifying bony cones which are found in Okapi and Giraffe on the frontal and parietal areas and in the Giraffe also in a median position. In my memoir of 1901 I spoke of such structures as "ossicusps," a term which I now wish to apply more generally, reserving the term "ossicone" for the peculiar separately ossifying cones of the Giraffidæ. 


\section{$2 \mathrm{BHL}$ Biodiversity Heritage Library}

Goeldi, Emi

lio Augusto. 1907. "On some new and insufficiently known Species of Marmoset Monkeys from the Amazonian Region." Proceedings of the Zoological Society of London 1907, 88-100.

https://doi.org/10.1111/j.1096-3642.1907.tb01801.x.

View This Item Online: $\underline{\text { https://www.biodiversitylibrary.org/item/97670 }}$

DOI: https://doi.org/10.1111/j.1096-3642.1907.tb01801.x

Permalink: https://www.biodiversitylibrary.org/partpdf/72467

\section{Holding Institution}

Smithsonian Libraries

\section{Sponsored by}

Biodiversity Heritage Library

\section{Copyright \& Reuse}

Copyright Status: Public domain. The BHL considers that this work is no longer under copyright protection.

This document was created from content at the Biodiversity Heritage Library, the world's largest open access digital library for biodiversity literature and archives. Visit BHL at https://www.biodiversitylibrary.org. 